\title{
Mechanical properties of particulate reinforced aluminium alloy matrix composite
}

\begin{abstract}
This paper discusses the mechanical properties of Titanium Carbide (TiC) particulate reinforced aluminium-silicon alloy matrix composite. TiC particulate reinforced LM6 alloy matrix composites were fabricated by carbon dioxide sand molding process with different particulate weight fraction. Tensile strength, hardness and microstructure studies were conducted to determine the maximum load, tensile strength, modulus of elasticity and fracture surface analysis have been performed to characterize the morphological aspects of the test samples after tensile testing. Hardness values are measured for the TiC reinforced LM6 alloy composites and it has been found that it gradually increases with increased addition of the reinforcement phase. The tensile strength of the composites increased with the increase percentage of $\mathrm{TiC}$ particulate.
\end{abstract}

Keyword: Fracture surface; LM6 alloy; Tensile; TiC particulate 